\title{
Use of groundwater flow model in the analysis of a creeping landslide in western Japan
}

1 Graduate School of Science and Engineering, Ehime University, Japan. E-mail: shrestha_h@hotmail.com

2 Faculty of Engineering, Ehime University, Japan.

To predict the movement of an existing creeping landslide, monitoring and analysis of hydrological parameters are crucial. This paper analyses the hydrological parameters of an existing creeping landslide site in western Japan. The groundwater flow and resulting fluctuation in pore water pressure at the slip layer of a sliding block was simulated using a groundwater flow model. A quasithree-dimensional factor of safety of the block was obtained by combining the groundwater model with slope stability analysis methods. The results show that for prediction purposes at a creeping landslide site the time series analysis using longterm data is of limited use, because the fluctuations of ground surface movement and hydrological parameters are not completely synchronized when the factor of safety of the slope soil is in the creep movement range. The ground surface movement rate dropped after each episode of relatively big movement, even when the hydrological parameters were constant. The factor of safety of the sliding block was more influenced by groundwater recharge from the hills than by rainfall. Pore water pressure fluctuation obtained from groundwater flow model resulting from specific rainfall events indicated better relations between fluctuations in pore water pressure and ground surface movement.

\section{Introduction}

Western Japan's Shikoku Island has a high density of active landslide sites. Of particular concern among these is a landslide known as the Nuta-Yone Landslide Site (NLS) near the border between Kochi and Tokushima prefectures (Figure 1). The NLS is located close to the Mikabu tectonic zone, and experiences frequent seismic activities. The geological features of the NLS are characterized by the Mikabu Geological Belt, which separates the Sambagawa and Chichibu Geological Belts. The primary bedrock of the landslide mass is greenstones of the Mikabu belt, which consists of less metamorphosed basalt, dolerite and metamorphic pyroclastic rocks. The NLS consists of two major clusters of landslides, known as Nuta and Yone. Each of them consists of several active sliding blocks. This study focuses on one of the blocks under the Nuta cluster. Monitoring of this site has been going on for the past four decades. Various preventative measures have also been taken during this time to

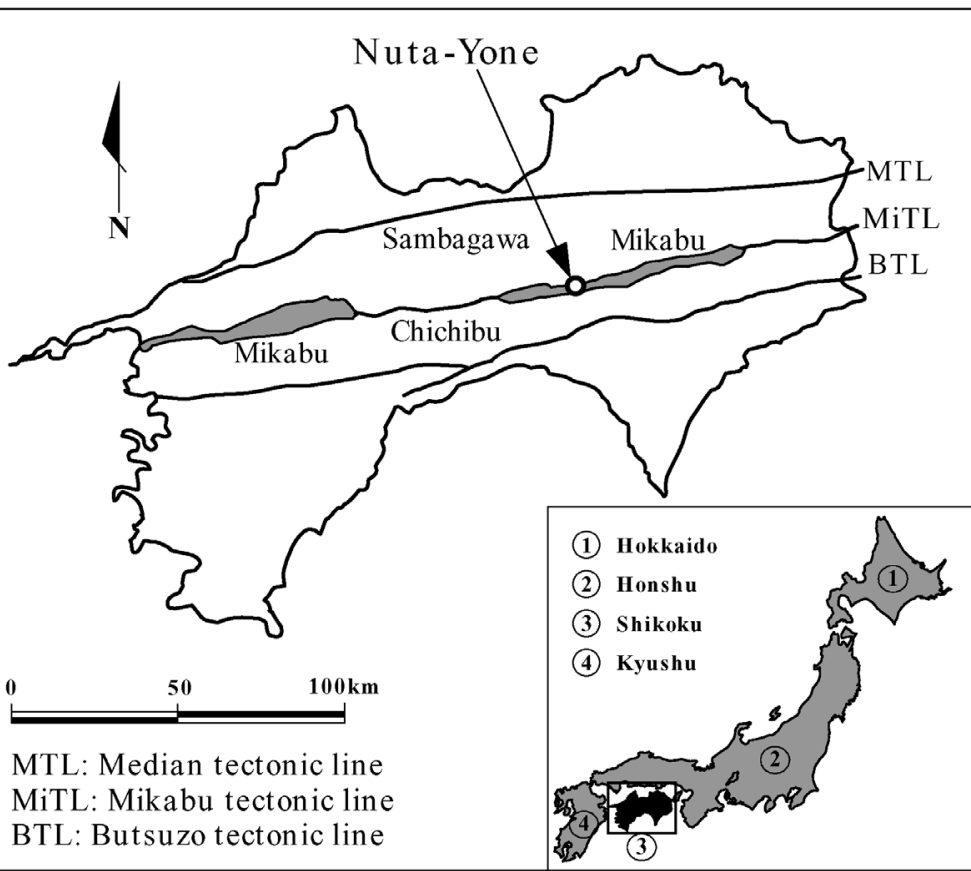

Figure 1 Map of Shikoku showing location of the Nuta-Yone Landslide Site.

impede the rate of ground movement at the NLS, but limited success has been achieved, although the rate of ground movement seems to have slowed. Lowering of the water table was achieved by constructing a network of underground horizontal drains, vertical collection wells and surface drains. Lowered pore water pressure at the slip surface has increased the factor of safety (FOS) of the sliding blocks, but due to the high rainfall rate and groundwater recharges from the hills above the NLS, the FOS of the sliding blocks is still in the creep movement zone. Consequently, the ground still moves every day, although at creeping rate. A program to further drain the hill slope by expanding the network of horizontal drains is under way.

In this study available relevant data of the NLS were collected and analyzed to find the relationship among the different parameters. A three-dimensional (3D) transient groundwater flow model of the site was constructed to simulate fluctuations in pore water pressure and the FOS at one of the sliding blocks at the NLS. The results showed that time series correlation analysis between hydrological parameters and ground surface movement (GSM) using long-term data at a creeping landslide site is of limited use for predicting future ground movement from hydrological data. As long as the FOS of the slope is in the creep movement zone, a creeping landslide may slide at a constant rate when hydrological parameters are fluctuating, and vice versa. Event-based modeling, however, showed better relations between pore water pressure and GSM, and also illustrated the reason for low correlation between rainfall and GSM at the NLS. 


\section{Methodology}

To understand the nature of collected data at the NLS, time-series analysis of the parameters was carried out. The parameters tested were rainfall, borehole water surface elevation (WSE) and GSM. Correlation analyses were carried out between (a) rainfall and WSE, (b) rainfall and GSM, and (c) WSE and GSM.

Borehole logs and borehole soil samples were checked to find the distribution of soil types in the study area. Based on the analysis of the data, 3D cross sections of the boreholes were plotted to obtain a continuous distribution of soil types within the study area. Based on laboratory test results, each soil type was assigned specific values of various hydrological parameters, such as specific storage and hydraulic conductivity.

The area of the NLS with the highest density of available pertinent data was selected for computer modeling (Figure 2). The circles in Figure 2 represent borehole locations. A suitable public domain computer code named Modular Three Dimensional Ground Water Flow and Transport Model (MODFLOW) was used for groundwater flow simulation (USGS, 2000). A transient 3D groundwater flow model of the study area was calibrated using measured water surface elevations at different boreholes as calibration values.

The modeling area consisted of two sliding blocks - N2-2 and N2-3, as shown in Figure 2. Both blocks are sliding towards the river (Minamidaiogawa) in a westerly direction. Based on the resulting head distribution of transient model run of a particular period, fluctuation in representative 3D pore water pressure at the slip surface of the N2-2 block for that period was calculated. The correlation between pore water pressure and GSM data was calculated for the period. There are several boreholes at the NLS used for monitoring landmass displacements. Based on the differential movement of boreholes, the three-dimensional slip surface of the N2-2 block was obtained. The N2-2 block was divided into equidistant sections. Using the resulting head distribution from the groundwater flow model, the FOS of each section for each day of simulation (26 sections for 35 days) was calculated by Janbu's two-dimensional slope stability analysis method (1956). The equivalent 3D FOS of the N22 block was calculated for each day of the simulation by using the area-weighted average method. Fluctuation in the equivalent 3D FOS of the N2-2 block was related to the correlation between rainfall and GSM at the NLS.

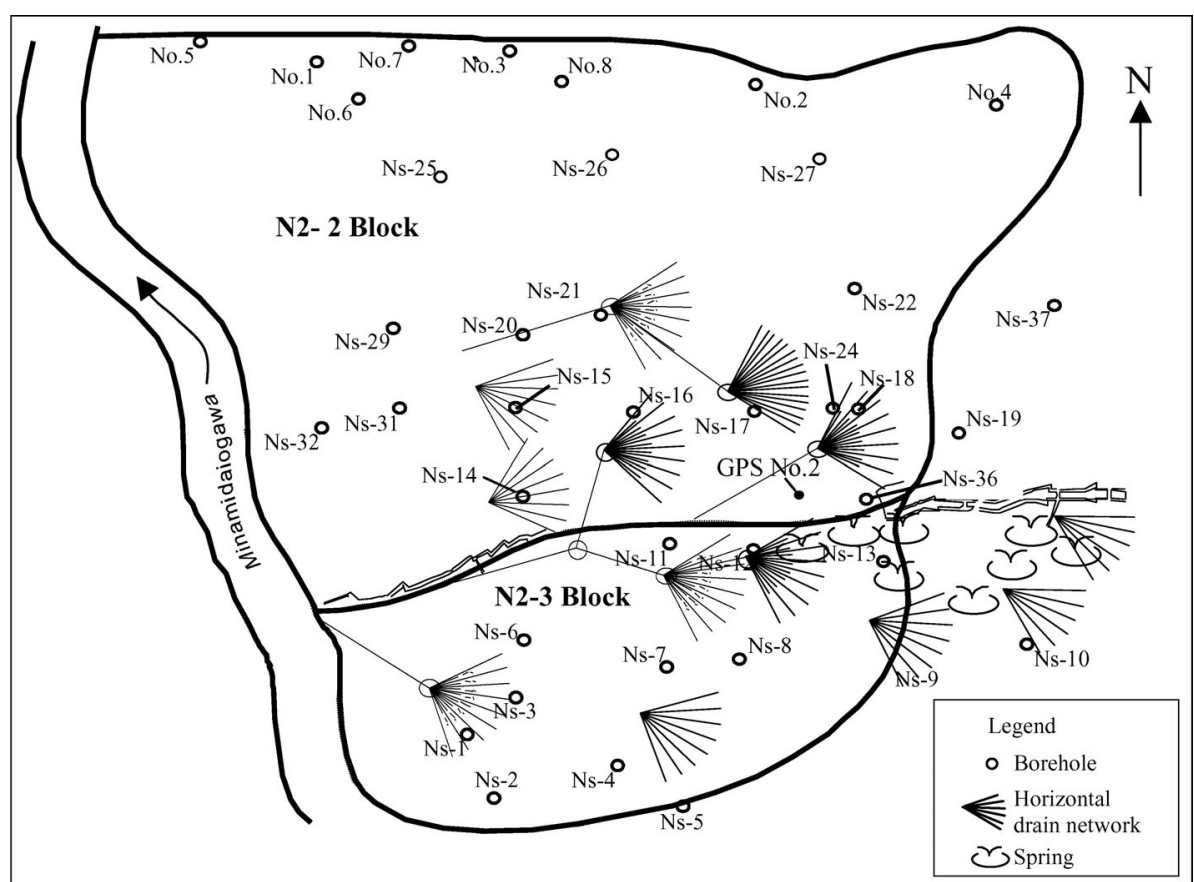

Figure 2 Area of Nuta-Yone Landslide Site selected for 3D groundwater modeling.

\section{Results and discussions}

The results and discussions related to time series analysis, correlation analysis, groundwater flow modeling, pore water pressure calculation and FOS calculations are as follows:

\section{Time series analysis}

Daily rainfall was recorded at the NLS using automatic rain gauge. The plot of rainfall records (Figure 3 ) showed several breaks in the data. The highest recorded 24-hour rainfall at the NLS occurred on September 24, 1998. To check the consistency of the rainfall data at the NLS, rainfall data from the two nearest meteorological stations, Kyojo and Motoyama, were collected and correlated with the NLS rainfall data. The correlations $\left(\mathrm{r}^{2}\right.$ value) between the annual rainfall at the NLS and Kyojo and that between the NLS and

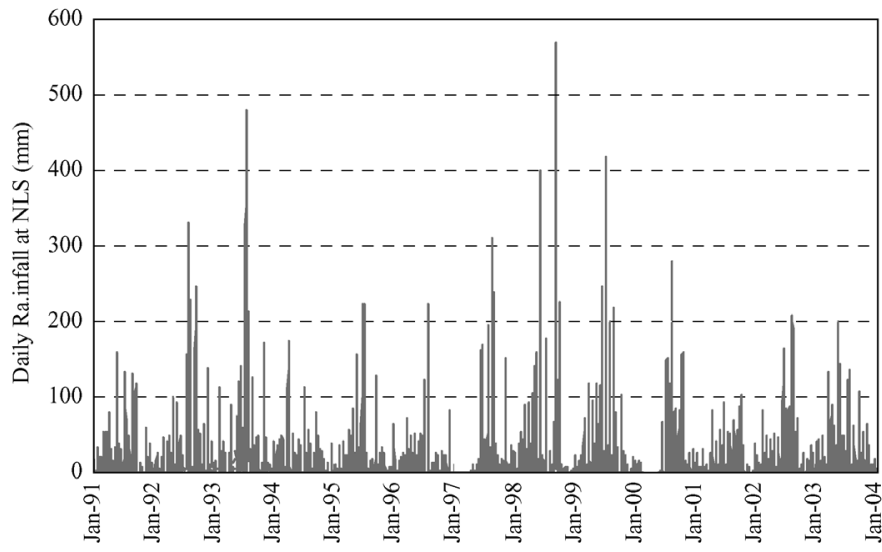

Figure 3 Daily rainfall at Nuta-Yone Landslide Site from 1991 to 2003.

Motoyama were 0.78 and 0.86 , respectively. However, the $\mathrm{r}^{2}$ values for daily rainfall between the NLS and Kyojo and between the NLS and Motoyama were 0.5 and 0.61 , respectively. The higher values for annual and the lower ones for daily rainfall indicate that the trend of rainfall at the NLS is the same as the trend in the region, but the correlations among the three rainfall stations are not strong enough for the missing rainfall values at the NLS to be filled by using data from the other stations. The reason for the lower correlation in daily data is perhaps the daily variations in temporal and spatial data.

The plotting of water surface elevation (above mean sea level) at the NLS at different boreholes showed breaks in the data (Figure 4). Some of the data breaks occurred at critical times, as when there are records of high intensity rainfall or a high rate of GSM. At most of the boreholes WSE were consistently higher before 1998. The drop in WSE at different boreholes before and after 1998 varied from less than $2 \mathrm{~m}$ to more than $20 \mathrm{~m}$. Lower WSE at the boreholes after 1998 can be attributed to the effects of a network of underground horizontal drains, vertical collection wells and surface drains. Most of the horizontal drains in the network went into operation around July 1998. The variation in the drop of WSE at different boreholes after 1998 depended on the closeness of a borehole to the drain network. Boreholes farthest from the 


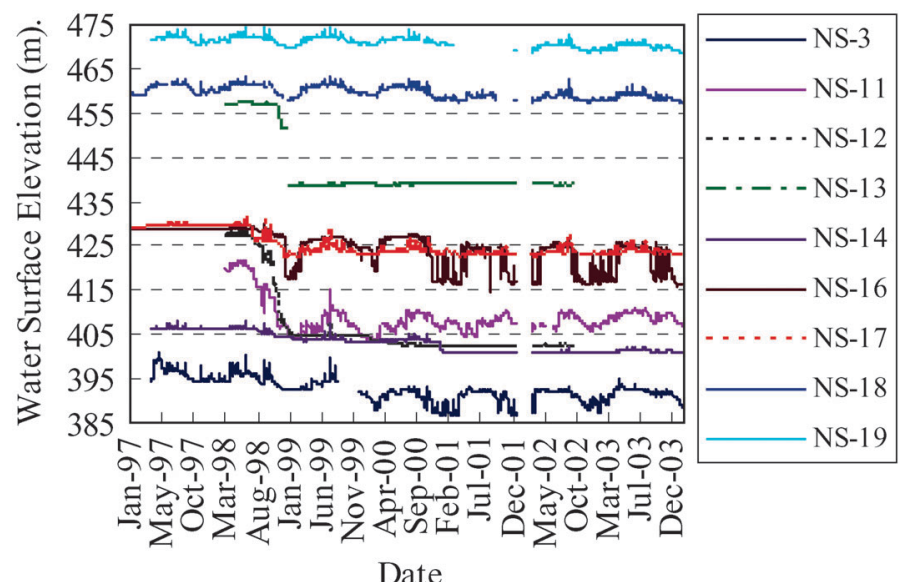

Figure 4 Water surface elevation at different boreholes at Nuta-Yone Landslide Site.

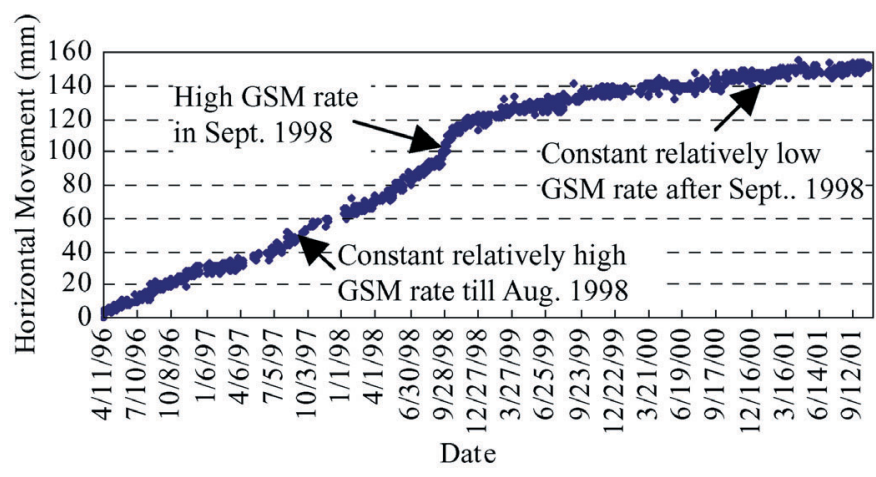

Figure 5 Horizontal movements of GPS No.2.

drain network displayed the lowest drop in WSE. For example, the average drop in WSE at Ns-19 and Ns-13, which are $32 \mathrm{~m}$ and $12 \mathrm{~m}$, respectively, from the nearest drain, were 0.2 and $17.4 \mathrm{~m}$, respectively, between 1998 and 1999.

The GSM at the NLS were monitored by various methods, including global positioning systems (GPS). GPS No. 2 is within the model area, as shown in Figure 2. As in the case of rainfall and WSE data, there are numerous data breaks in the GSM data. Again, some of the data breaks were during critical times, when there are records of high intensity rainfall. Plotting of horizontal radial GSM at GPS No.2 showed that there is daily fluctuation in the data. The GSM data monitored by GPS show daily fluctuations in studies carried out by other researchers also (Chadwick et al., 2005 and Coe et al., 2000). However, the range of daily variation is within a few millimeters. The rate of GSM at the NLS was fairly constant $(0.1 \mathrm{~mm} /$ day $)$ from April 1996 to August 1998 (Figure 5). The GSM rate suddenly increased to $0.7 \mathrm{~mm} /$ day in September 1998, which can be attributed to the record high rainfall in that period, as shown in Figure 3. The horizontal radial GSM rate declined gradually and consistently after September 1998. The average GSM rate in 1999 and 2000 was 0.05 $\mathrm{mm} /$ day, which further fell to $0.02 \mathrm{~mm} /$ day in 2001 . The decline in GSM rate at the NLS can be attributed to the lowering of the water table elevation at the NLS and the consequent lowering of pore water pressure at the slip surfaces of the sliding blocks by the network of horizontal and surface drains.

\section{Correlation analysis}

Correlation analyses between daily values of rainfall, borehole WSE and horizontal GSM were conducted with two variables at a time. The results of the analyses showed that the correlation between any of the two variables was low. One of the reasons for the low correlation is the data breaks at critical times: All three data sets have several breaks in the data. The other reason could simply be faulty data. There are many examples from the monitoring of different boreholes when the quality of the WSE data is questionable. Although the overall trend of GSM data indicated a gradual departure of GPS location from the initial position, the daily horizontal distance between the initial location and the new location fluctuated.

The relation between daily rainfall and daily WSE at the boreholes was found to be non-existent (average $\mathrm{r}^{2}$ value $=0.1$ ) when the overall data were considered, and there was very little improvement in correlation even when time lags between rainfall and increase in WSE were considered. The time lag between a rainfall event and consequent rise in WSE at boreholes is a function of several interdependent variables, such as location and pattern of rainfall, antecedent moisture content and infiltration capacity of top soil, ground cover, and horizontal and vertical hydraulic conductivity of the soil materials. Shiraishi et al. (2003) found that the time lag between peak rainfall event and peak rise in WSE at different boreholes at the NLS varied up to 40 days. The result of this analysis showed that a rainfall event of a specific intensity or amount cannot be used to reliably predict changes in WSE at boreholes at the NLS. The relation between rainfall and WSE may improve if more rainfall stations at different locations are installed at the NLS.

Correlation (using all available data) between daily rainfall and daily horizontal GSM data was extremely low, even when time lags were considered $\left(r^{2}=0.11\right)$ when a specific constant time lag was assumed. There was slight, although very marginal, improvement in the $\mathrm{r}^{2}$ value when selective time lag was used. Under selective time lag, any rise in GSM between 0 to 8 days after a rainfall event was associated with the rainfall event. With selective time lag, the average $r^{2}$ value between rainfall and GSM was 0.25. On a year-to-year basis, the correlation between daily rainfall and daily horizontal GSM varied from 0.5 to 0.1 . The main reason for the low correlation is perhaps the nature of the creeping landslide. Patton (1984) indicated that a creeping landslide keeps sliding at creep rate as long as the FOS of the sliding mass is within a range slightly above 1 . The landslide at the NLS is of the creep type and has a high groundwater table. A rainfall event that may last only one day can keep the FOS value of the sliding block within the range of creep movement for several days. There are hills above the N2-2 sliding block. Groundwater recharge from the hills to the slip surface of the N2-2 block can keep the FOS of the N2-2 block in the creep range even when there is no rainfall at the NLS for several days. So, the land keeps sliding at creep rate even when there is no rainfall event. This phenomenon brings the correlation value down. Another reason for the decrease in correlation value is the effect of a following rainfall event before the effect of a preceding rainfall ceases. In hydrological analysis, when two or more specific rainfall events occur very close to each other, the resulting hydrograph is a complex one, and there are specific techniques to separate the effects of each rainfall event on the hydrograph. However, in the analysis of the effects of two or more storm events occurring close to each other on GSM there are no such straightforward techniques.

Correlations between WSE and horizontal GSM at GPS No. 2 were low when all the available daily GSM data and daily WSE data at the NLS were considered $\left(\mathrm{r}^{2}\right.$ values $\left.=0.12\right)$. Correlation was carried out again for the data of September 1998, which exhibited a dif-

Table 1 r2 values between water surface elevation and ground surface movement at different boreholes with time-shift of 4 days.

\begin{tabular}{|c|c|c|c|c|c|c|c|c|c|c|c|c|}
\hline Borehole & Ns-3 & Ns-12 & Ns-13 & Ns-14 & Ns-16 & Ns-17 & Ns-19 & No. 2 & No.4 & No.5 & No.7 & No.8 \\
\hline $\mathbf{r}^{2}$ value & 0.37 & 0.44 & 0.04 & 0.47 & 0.47 & 0.49 & 0.46 & 0.43 & 0.52 & 0.18 & 0.35 & 0.53 \\
\hline
\end{tabular}


ferent rate of GSM compared to other times (Figure 5). The reasons for selecting this time were that (a) the GSM rate during this time was the highest, (b) WSE data were unbroken at most of the boreholes, and (c) GSM data were unbroken. For September 1998, the average $r^{2}$ values between WSE and GSM with a time shift of four days was 0.35 (Table 1). At Ns-13, the $\mathrm{r}^{2}$ value was higher (0.42), with a time shift of five days, which again shows the heterogeneous nature of the geological formation at the NLS. The lower $\mathrm{r}^{2}$ value at borehole No.5 is probably due to its location, which is far from the GPS No.2 location, and its vicinity to the Minamidaiogawa. WSE at borehole No. 5 is more influenced by the river water elevation than by general groundwater flow in the N2-2 block. At borehole No.8 the $\mathrm{r}^{2}$ value was 0.53 for this time period. This improvement in correlation between WSE and GSM shows a link between the borehole WSE and GSM.

Although rainfall recharge is the basic cause of landslides at NLS, the results of the correlation analyses indicated that the time series data of rainfall are of limited use in predicting creep movement at the study site. There are many other competing variables that affect the relation of rainfall with WSE and GSM. The time series WSE data at different boreholes do show relation with GSM, although with a time shift. However, due to the heterogeneous nature of the soil properties, WSE at each borehole showed different degrees of relationship with GSM. Hence, predicting GSM based on WSE at specific boreholes will not be very reliable.

\section{Groundwater flow modeling}

Using a public domain finite difference method-based computer code called MODFLOW, a 3D groundwater flow model of an area inclosing sliding blocks N2-2 and N2-3 was developed. The model domain was divided into 75 rows and 80 columns (horizontally), each of size $6 \mathrm{~m} \times 6 \mathrm{~m}$, and into three layers. The vertical division of the model depended on the changes in soil type, as indicated by changes in hydraulic conductivity $(\mathrm{K})$ of the soil. The thicknessess of each soil type varied spatially, so the thickness of each model cell varied accordingly. The boundary conditions of the model were set based on topography and other field values. The model cells that lie to the west of Minamidaiogawa were made inactive, since these cells do not contribute to groundwater flow in the area covered by the N2-2 and N2-3 blocks. The existing horizontal drains at the study site were set as drain cells in the model. Known springs were modeled as constant head cells. Flow into the model depended on the head value assigned to the cells representing the hills in the eastern boundary; flow out of the model depended on the head value assigned to the cells representing Minamidaiogawa on the western boundary. In the transient model, the head values assigned to the eastern and western boundary cells depended on the expected ratio of rainfall recharge for the particular stress period. Figure 6 is a 3D representation of the model domain.

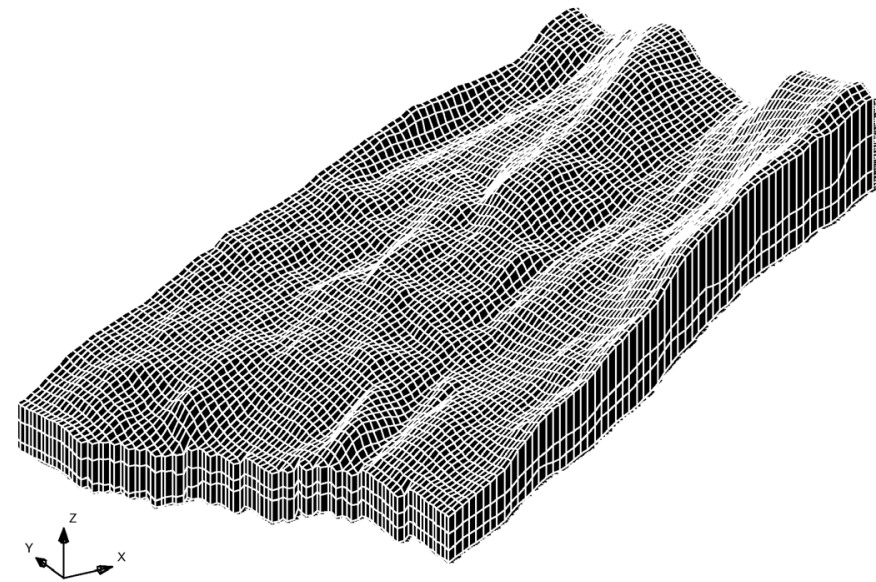

Figure 6 Three dimensional view of model domain at Nuta-Yone Landslide Site.

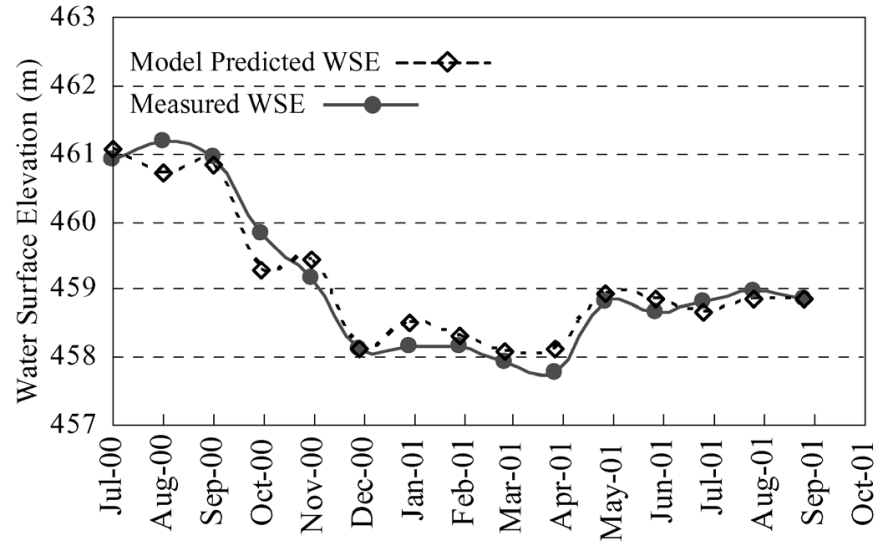

Figure 7 Model predicted and the measured water surface elevation at NS-18.

For calibration purpose, the transient model was constructed with 16 stress periods. The head values at different boreholes from July 2000 to October 2001 (16 months) were used as the calibration values for the transient model. Figure 7 is an example of match between measured and model-predicted WSE values at one of the boreholes (Ns-18, row 35, column 61). The application of the model indicated that the effect of the horizontal drains in reducing WSE at different boreholes depended on various factors, such as (a) hydraulic conductivity distribution between the drain and the boreholes, (b) the distance of the borehole from the drain, and (c) recharge rate in the vicinity of the drains. Moreover, in transient simulation, the recharge rate varied in each stress period. Hence, the minimum distance for a drain to have an effect in drop in WSE varied from one drain set to the next, and from one stress period to the next.

\section{Pore water pressure}

The area of the model representing sliding block N2-2 was divided into 26 equidistant sections. The slip surface elevation of the N2-2 block at each section was obtained to create a 3D representation of the sliding soil mass. The calibrated transient model was run to obtain head distribution in the N2-2 block area from August 27 to September 30, 1998, using 35 stress periods, each stress period representing one day. The difference between the resulting hydraulic head (not WSE) and the slip surface elevation was used to calculate the pore water pressure at the slip surface at each model cell. At locations where the slip surface was located in a model cell in lower layers, the resulting hydraulic head from the cell of the corresponding layer was used to calculate the pore water pressure. A representative average 3D pore water pressure at the slip surface of the whole block for each stress period was calculated by taking the area-weighted average of each section of the N2-2 block. A plot of variation in 3D pore water pressure at the slip surface of the N2-2 block and GSM data for the same time shows a better relation between the two variables (Figure 8); the $\mathrm{r}^{2}$ value for the 35 stress periods was 0.45 , as against the average $r^{2}$ value of 0.35 between borehole WSE and

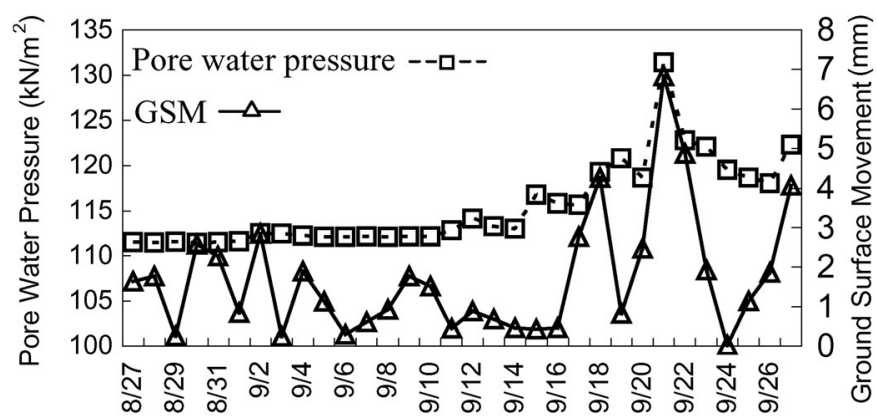

Figure 8 Fluctuation of pore water pressure and ground surface movement at the N2-2 block in the simulation period. 
GSM. The pore water pressure resulting from the groundwater model incorporates the combined effects of rainfall recharge and groundwater recharge from the hills above the model area to the cells representing the slip surface of the sliding block. The relatively better correlation between variation in 3D pore water pressure and GSM data seems to indicate that pore water pressure is a better indicator of potential movement of a creeping landslide than rainfall or WSE. There will always be a limit in the correlation in the day-to-day scale time series analysis between pore water pressure and GSM data at a creeping landslide site because, as Figure 8 shows, after each episode of relatively big GSM the rate of GSM drops, even if the pore water pressure remains constant. The reason for the drop in GSM is not clear. There could be several reasons, one of them being change in the slope soil after each episode of landmass displacement.

\section{Factor of safety (FOS)}

At a creeping landslide site the slope soil keeps sliding down as long as the pore water pressure is high enough to maintain an FOS value in the creep movement range, regardless of whether there is rainfall or not. To test if the resulting FOS values of the N2-2 block lie in the range of creep landslide, using the output from the 3D groundwater flow model, the FOS of each of the 26 sections of the N2-2 block were calculated separately for each day from August 27 to September 17, 1998, with Janbu's two-dimensional slope stability analysis method. The two-dimensional FOS values of each section for each stress period were combined to obtain fluctuation in the equivalent 3D FOS value of the entire N2-2 block by using the method of Lambe and Whitman (1979). In this method, the equivalent 3D FOS is calculated as the area-weighted average of each of the two-dimensional FOS values. Loehr et al. (2004) proposed a new method of calculating quasi-3D FOS, called the "resistance weighted method," which is more suitable for simple and complex sliding masses with bigger sections at the edges but involves more calculations. The N2-2 sliding block was relatively simple, with smaller sections at the edges and bigger sections at the central portion of the mass; hence Lambe and Whitman's method was considered suitable for this study. The results of this analysis showed that the equivalent 3D FOS of the N2-2 block was indeed within the range of creep movement. As shown in Figure 9, the 3D FOS of the N2-2 block fluctuated between 1.04 and 1.02. This range of fluctuation is within the creep movement zone indicated by various researchers (Patton, 1984; Yagi et al., 1989). Between August 27 and September 17, rainfall occurred only on four days (September 5, 6, 14 and 15), and the average rate of rainfall during this time was very low $(2.3 \mathrm{~mm} /$ day $)$. On 18 out of 22 days there was no rainfall at all, but the FOS did not increase enough to make the slope stable. The reason for the sustained low FOS value is the groundwater recharge from the hills above the N2-2 block. The FOS did decrease as a result of rainfall events, but not enough to cause a complete collapse of the slope. Figure 9 clearly shows the reason for the low correlation between rainfall and GSM at a creeping landslide site. In fact, the $\mathrm{r}^{2}$ value between rainfall and GSM for this range of data was 0.09 , showing no apparent relation between them.

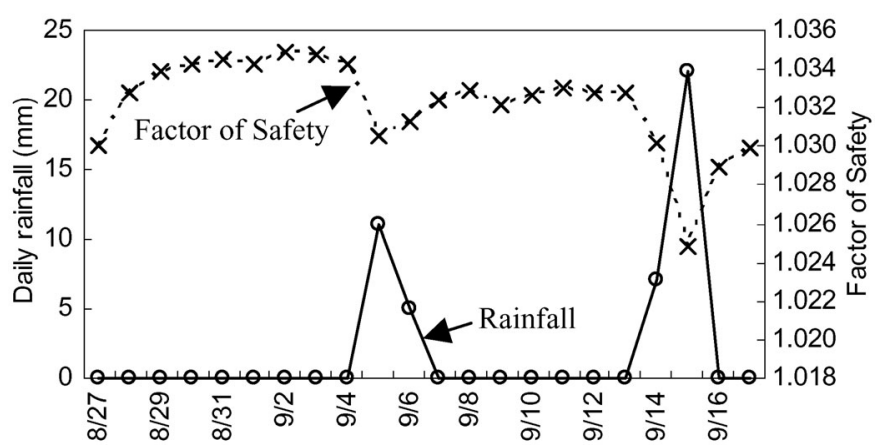

Figure 9 Rainfall and factor of safety at the N2-2 block.

\section{Conclusions}

Different available hydrological time series data were analyzed to find their relation to creeping landslide movement data at the NutaYone Landslide Site. Rainfall recharge is a basic cause of landslides at the study site, but due to data breaks, extreme variation in time lag between rainfall periods and the associated rise in water surface elevation at different locations, the available data showed very poor correlation between rainfall and ground surface movement. The relation between borehole water surface elevation data and ground surface movement data was somewhat better, but the degree of relation varied with different boreholes. A 3D groundwater flow model of the study site was prepared. Based on the results of this model, 3D pore water pressure at the slip surface of the N2-2 block was calculated for a particular case. The study found better correlation between 3D pore water pressure and creeping movement at the Nuta-Yone Landslide Site. The low fluctuation in the equivalent three-dimensional factor of safety of the N2-2 block illustrated the reason for the low correlation between the basic hydrological parameters and ground surface movement at creeping landslide sites. The following conclusions were drawn based on the results of this study:

a) Due to creeping nature of landslides at the Nuta-Yone Landslide Site, slope soil keeps moving even when there is no rainfall, or even if water surface elevations at boreholes keep falling, as long as the FOS of the hill slope is within the creep movement range.

b) The relation between borehole water surface elevation and ground surface movement at the NLS is weak. So, predicting the landslide potential based on measured hydrological data at a few landslide locations will not be very reliable.

c) Three-dimensional groundwater flow modeling of a hill slope can integrate the effects of variations in multiple hydro-geological parameters. The three-dimensional pore water pressure of the sliding mass, obtained from the results of the model, seems to be a better indicator of the potential of movement of a creeping landslide, compared to other hydrological parameters.

\section{Acknowledgements}

Aratani Civil Engineering Consultants, Matsuyama Office, Shikoku, Japan, provided basic data for this study.

\section{References}

Chadwick, J. N. Glenn, G. Thackray and S. Dorsch, (2005), Landslide Surveillance: New Tools for an Old Problem, EOS, American Geophysical Union, EOS Vol. 86, No. 11, 15 March 2005.

Coe, J. A., J.W. Godt, W.L. Ellis, W.Z. Savage, P.S. Powers, D.J. Varnes and P. Tachker, (2000) Seasonal movement of the Slumgullion landslide as determined from GPS observations, July 1998-July 1999, USGS OpenFile Report 00-101.

Janbu, N., Bjerrum, L., and Kjaernsli, B. (1956), Soil mechanics applied to some engineering problems, Norwegian Geotechnical Institute, Publ. No. 16.

Lambe, T. W. and Whitman, V. R. (1979). Soil Mechanics, SI version, Wiley, New York, p. 370.

Loehr, J.E., McCoy, B.F. and Wright, S.G. (2004) Quasi-three-dimensional slope stability analysis method for general sliding bodies, Journal of Geotechnical and Geoenvironmental Engineering, ASCE, Volume 130, Number 6, June 2004, p. 551-560.

Patton, F.D., Climate, (1984), Ground-water pressures and stability analyses of landslides, IV International Symposium on Landslides, Vol. 3.

Shiraishi, H., Yatabe, R., and Bhandary, N.P., (2003) Displacement mechanism of large-scale landslides from the viewpoint of underground water behavior, Proc. Intl. Conf. in Slope Engineering, Hong Kong, p 219-224.

USGS (2000) Modular three dimensional finite difference ground water flow and transport model (MODFLOW 2000), http://water.usgs.gov/nrp/ gwsoftware/modflow2000/modflow2000.html 
Yagi, N. Enoki, M., and Yatabe, R., (1989), Stability analysis on landslides in fracture zone, Proc. the Japan-China Symposium on Landslides and Debris Flows, Niigata, Japan, p. 147-152.

Dr. Hari Krishna Shrestha received BS (Hydrology) from Tarleton State University, Texas, USA, MS (Hydrology) from New Mexico Tech, New Mexico, USA, and PhD (Engineering) from Ehime University, Japan. He has worked as consultant hydrologist in numerous projects in USA and Nepal. Dr. Shrestha is an Associate Professor at Nepal Engineering College, Nepal, and is associated with Ehime University. He has published over 20 technical papers. His research interests are in groundwater simulation, river hydrology and landslides.

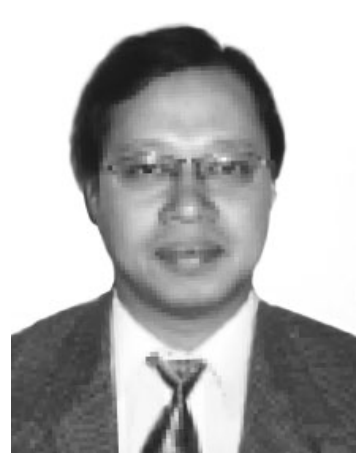

Prof. Ryuichi Yatabe is a Kyoto University graduate. He was awarded PhD (Engineering) degree in 1987 by Kyoto University. As a researcher and an academician in the field of geotechnical engineering, he has done substantial works in landslides and related soil failure problems including slope stability analysis. He has published over 100 technical papers, mostly in landslide- related issues. His research interests include landslides, debris flows, slope failures, geo-environmental problems, etc.

Dr. Netra Prakash Bhandary graduated from Aligarh Muslim University of India in 1993. He joined Ehime University as a postgraduate student in 1998, and completed MEng degree in 2000 and $P h D$ (Engineering) degree in 2003, specializing in landslides and their stability. He has published more than 40 technical papers mostly focusing on landslides and slope failures. He is currently working on creep behavior of clayey soils in residual state of shear and its implications in landslide behaviors. His research interests include creeping landslides, slope stability, strength properties of expansive clays, and clay mineralogy.
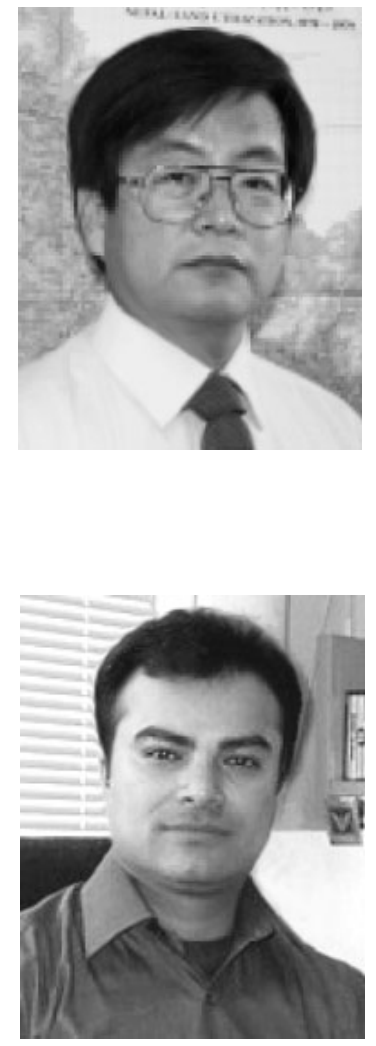

\section{Thermodynamics of Natural Systems}

\section{Greg Anderson}

Thermodynamics deals with energy levels and the transfer of energy between states of matter, and is therefore fundamental to all branches of science. This new edition provides a relatively advanced treatment of the subject, specifically tailored for the interests of the Earth sciences.

Beginning at an elementary level, the first four chapters explain all necessary concepts, using a simple graphical approach. Throughout the rest of the book the author emphasizes the use of thermodynamics to construct mathematical simulations of real systems. This helps to make the many abstract concepts easier to understand. Many computer programs are mentioned and used throughout the text, especially SUPCRT92, a widely used source of thermodynamic data.

Building on the more elementary material in the first edition, this textbook will be ideal for advanced undergraduate and graduate students in geology, geochemistry, geophysics, and environmental science.

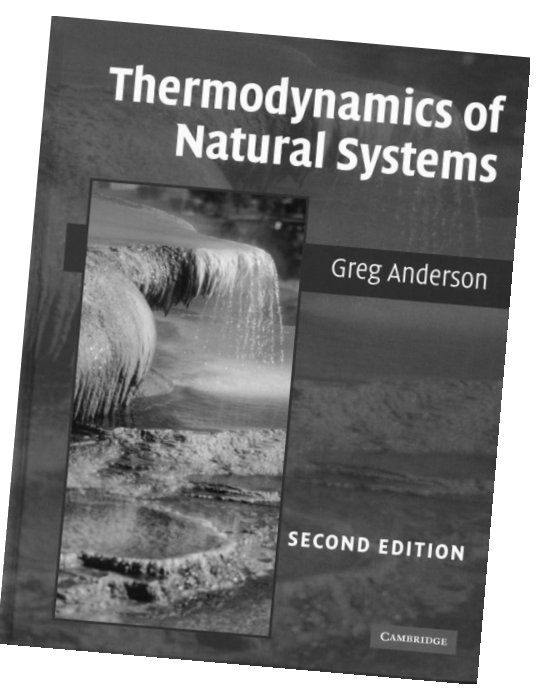

Cambridge University Press

www.cambridge.org

July 2005

$£ 45.00$ (US $\$ 80.00$ )

ISBN 0521847729

CAMBRIDGE 